\title{
A Aliança do Pacífico: soberania nacional e estratégia de integração na América Latina?1
}

The Pacific Alliance: national sovereignty and integration strategy in Latin America?

\author{
Ana María Suárez Romero²
}

\section{RESUMO}

A América Latina tem sido tradicionalmente caracterizada pela fragmentação política, a heterogeneidade e por não ter um projeto de integração único. O objetivo deste trabalho é analisar a Aliança do Pacífico como mecanismo de integração - criação, objetivos e progressos - e sua relação com as iniciativas de integração latino-americanas existentes desde os anos 90, como o MERCOSUL, UNASUL e ALBA.

Palavras- chave: Aliança do Pacífico; América Latina; Integração Regional.

\begin{abstract}
Latin America has traditionally been characterized by the political fragmentation, heterogeneity and for not having a single integration project. This work aims to analyze the Pacific Alliance as integration mechanisms - its creation, its objectives and its progresses - and its relation with the Latino American integration initiatives existing from 90s, like Mercosur, UNASUL and the ALBA.
\end{abstract}

Keywords: Pacific Alliance; Latin America; Regional Integration.

\section{Introdução}

As relações internacionais da América Latina nos últimos anos têm se caracterizado por várias experiências, tanto de concertação, de integração regional e/ou ligações inter-regionais. Estes têm sido baseados no surgimento de novas formas de diplomacia multilateral ou concertação direta entre os governos latino-americanos para a gestão coletiva dos problemas internacionais, experiências que, pelo menos no início da década de 1990, mostrou um viés marcadamente informal e evolutivo (TOMASSINI, 1990:17). As novas formas de diálogo direto entre os governos latino-americanos ou diplomacia multilateral de alto nível, com a cooperação política como o eixo principal, ter ajudado a facilitar a gestão coletiva de questões internacionais de importância para a região, ou para grupos específicos de países.

\footnotetext{
${ }^{1}$ Este artigo faz parte da comunicação apresentada na I Jornada de Relações Internacionais do NEIBA - I JORNEIBA 16/04/2014.

2 Mestranda do Programa de Pós-Graduação em Relações Internacionais “San Tiago Dantas” (UNESP UNICAMP - PUC/SP). Economista pela Universidade dos Llanos da Colômbia, São Carlos, Brasil.
} 
A estrutura do poder mundial e as características da economia internacional apontou para os países latino-americanos a necessidade de reforçar as estratégias de participação seletiva no sistema internacional, que os guiaria para reduzir riscos e aproveitar as novas oportunidades (TOMASSINI, 1985:21).

A nova fase do processo de integração regional na América Latina é chamada por alguns analistas como um regionalismo pós-liberal ou pós-neoliberal, superando o modelo de regionalismo aberto dos anos 90 (SANAHUJA, 2008; SERBIN, 2010:1). De acordo com Serbin (2010), a partir de finais dos anos 90 e início do século XXI, foi desenvolvida uma nova conjuntura regional marcada pela ascensão de governos progressistas e de esquerda, e a questão da imposição da visão neoliberal do Consenso de Washington. 0 desenvolvimento de diversas formas de nacionalismo e rejeição de intervenção hegemônica de atores extra-regionais, especialmente os Estados Unidos, promoveu a reafirmação da soberania nacional na sua concepção tradicional ${ }^{3}$.

A localização geográfica da região, especialmente na América do Sul, rodeada por os oceanos Atlântico e Pacífico oferecem vantagens geoestratégicas, uma grande quantidade de recursos naturais (tanto no interior continental como em sua plataforma marítima). Padula (2013) aponta que na região se encontram desafios geográficos naturais para a integração física, tais como a Amazônia e os Andes (perto do Pacífico), que entre outros fatores, ao longo da história têm promovido um maior uso e desenvolvimento da vertente atlântica pela articulação e o comércio entre os países do interior, e de estes com a Europa e os Estados Unidos.

A consolidação das iniciativas latino-americanas mostra que a região começou um processo de ordenação com mais autonomia, no entanto prevalecem diferenças entre seus Estados, algumas vezes marcadas por tendências nacionalistas e/ou populistas. Segundo Sanahuja (2009:18) os processos de integração na região carecem de mecanismos de tomada de decisões, de legitimidade e de controle adequados, o que

\footnotetext{
3 "La soberanía nacional en el sentido westfaliano debe ser entendida, desde sus orígenes, como un mecanismo que permite a los Estados lidiar con su seguridad y con los conflictos bélicos con otras naciones soberanas, en tanto la soberanía nacional se constituyó en el eje tanto de la defensa de los intereses nacionales como, eventualmente, de una normatividad internacional que permitiese regular la guerra y los conflictos entre naciones" (SERBIN, 2010:3)
} 
gera fraqueza e falta de eficácia nas instituições regionais. Esta fraqueza é assumida pelo autor mais como um sintoma que como uma causa na medida em que:

Se relaciona con el marcado nacionalismo y la concepción "westfaliana" o tradicional de la soberanía que caracteriza a la cultura política latinoamericana. Esa concepción recorre toda la región, y se explica por la necesidad de preservar cierto margen de maniobra en la política nacional y la defensa de los intereses nacionales frente a los países vecinos, especialmente cuando existen marcadas asimetrías de tamaño, poder y riqueza (SANAHUJA, 2009:18-19).

Os aspectos geográficos e as diferenças acima mencionadas têm gerado a divisão da região no eixo do Pacífico e no eixo do Atlântico, o primeiro composto por México, Colômbia, Peru e Chile com a Aliança do Pacífico, e a segunda com a Venezuela, Uruguai, Paraguai, Brasil e Argentina com iniciativas como a ALBA e o MERCOSUL. Este artigo tem como objetivo analisar a Aliança do Pacífico como mecanismo de integração, seus objetivos, progressos e sua relação com as iniciativas de integração existentes na região. Na primeira parte é apresentada uma descrição da Aliança do Pacífico, a sua criação e as atividades desenvolvidas. Na segunda parte através de uma revisão da literatura é abordada a Aliança dentro da dinâmica das iniciativas de integração latinoamericanas existentes desde os anos 90, buscando identificar o seu potencial para interagir como iniciativas mutuamente complementares ou excludentes.

\section{Aliança do Pacífico: criação e avanços}

A Aliança do Pacífico é um mecanismo de integração econômica e comercial formado por Colômbia, Chile, México e Peru, criado em 28 de abril de $2011^{4}$ e formalizada num Acordo Macro em junho de 20125. Além dos membros plenos, a Aliança tem os países da Costa Rica e o Panamá como Estados Observadores candidatos a membros plenos e 28 países observadores ${ }^{6}$.

4 Ver "Declaración de Lima para la integración profunda: Declaración Presidencial sobre la Alianza del Pacífico".
Disponível em: http://alianzapacifico.net/documents/AP_Declaracion_Lima_I_Cumbre.pdf.
5 Ver "Acuerdo Marco de la Alianza del Pacífico". Se definen los requisitos para la adhesión de nuevos miembros, los
objetivos y acciones, establecimiento de Consejo de Ministros y atribuciones, la Presidencia Pro Tempore, entre otros
puntos. Disponível em: http://alianzapacifico.net/documents/2014/Acuerdo_Comercial.pdf y “Declaración de Paranal
- IV Cumbre Alianza del Pacífico" Observatorio Paranal, Antofagasta, Chile. Disponível em:
http://alianzapacifico.net/documents/Declaracion_de_Paranal.pdf
6 Uruguai, Equador, Canadá, Guatemala, Paraguai, Honduras, El Salvador, Estados Unidos, República Dominicana,
Espanha, França, Holanda, Portugal, Turquia, Alemanha, Japão, China, Coréia do Sul, Austrália, Nova Zelândia, Itália,
Reino Unido, Suíça, Finlândia, Índia, Israel, Marrocos e Cingapura. Os países observadores juntamente com os países
membros compartilham os princípios e objetivos estabelecidos no Acordo Marco. Para ser um país observador o 
A Aliança tem como objetivos: Criar uma área de integração profunda para avançar progressivamente para a livre circulação de mercadorias, serviços, capitais e pessoas; Impulsionar ainda mais o crescimento, o desenvolvimento e a competitividade das economias das partes, com vista a um maior bem-estar, a superação da desigualdade econômica e a inclusão social de seus habitantes; e Tornar-se uma plataforma de articulação política, de integração econômica e comercial, e de projeção para o mundo, com especial ênfase na região Ásia-Pacífico.

Desde a sua criação foram desenvolvidas VIII Cúpulas Presidenciais, em que os países membros avaliaram os avanços da Aliança, consolidaram novos acordos e executaram atividades complementares. É possível definir que esta iniciativa é baseada em um modelo de regionalismo liberal, no que prevalece o âmbito econômico vigente ao político ou social, com um cenário que aceita o pragmatismo e a flexibilidade ao invés de um aprofundamento institucional de integração e cooperação (MUÑOZ, 2012). A capacidade de oferta, desenvolvimento tecnológico e logístico pode se tornar limitações para sua inserção em fluxos internacionais de comércio, investimento e tecnologia.

Em termos de números7, os quatro países totalizam uma população de 212 milhões, com um PIB per capita de US\$10.000, são o sétimo maior exportador mundial e se eles foram considerados como um único país seria a oitava maior economia. De acordo com o Instituto para a Integração da América Latina e do Caribe-INTAL (2011), o comércio entre Chile, Colômbia, México e Peru não era relevante, para representar entre $2 \%$ e $3 \%$ do comércio total ao conjunto dos países nos últimos 10 anos. Isto pode ser explicado pela semelhança em dotações de fatores e o tipo de especialização em comércio internacional dos países andinos, prevalecendo às exportações das commodities. Para o México, a Aliança do Pacífico envolve um esforço para diversificar os seus mercados ${ }^{8}$, uma vez que seu comércio está concentrado com parceiros do Acordo de Livre Comércio de América do Norte-TLCAN (INTAL, 2011).

candidato deve ter acordos comerciais com dois dos países membros. São admitidos com a aprovação unânime do Conselho de Ministros, que por sua vez, define os termos de sua participação.

7 Ver Que es la Alianza?-Valor estratégico: Disponível em: $<$ http://alianzapacifico.net/que es la alianza/valor-estrategico/>

80 modelo de integração latino-americano chamado "novo regionalismo" que se desenvolveu após 1990, reativou os processos de integração centro-americana, andina e do caribe, que no que diz respeito à política comercial foi baseado na abertura de regionalismo aberto (1990-2005). Dois países que optaram por estratégias individuais se destacaram, por um lado o México, que procurou estabelecer uma 
No que diz respeito às relações entre os países membros da Aliança do Pacífico e a região Ásia-Pacífico é de notar que México, Peru e Chile fazem parte do Fórum de Cooperação Ásia-Pacífico - APEC (Ásia-Pacific Economic Cooperation), além do que o Chile e Peru são membros do Acordo de Associação Transpacífico - TPP (Trans-Pacific Partnership), iniciando negociações desde os anos 2005 e 2010 respectivamente. 0 México foi formalmente convidado para começar as negociações do TPP em junho de 2012, em resposta a seu interesse em participar do processo em novembro do ano anterior.

\section{Iniciativas de Integração latino-americana dos anos 90 e a Aliança do Pacífico}

A integração da década de 90 na América Latina foi caracterizada por uma estratégia baseada em um regionalismo aberto, com a qual a integração e a cooperação são revitalizadas, surgindo novos acordos de livre comércio e novas formas de colaboração em áreas como o desenvolvimento de infraestrutura, integração energética, desenvolvimento tecnológico, entre outros.

A necessidade de consolidar novos líderes e um novo esquema para a coordenação e integração regional na América do Sul em particular, caracterizando-se por uma maior autonomia na tomada das decisões, gerou um novo mapa geopolítico na atualidade (MUÑOZ, 2012). Esta necessidade foi exposta de alguma forma por Tomassini (1985:21), o qual indicou o desafio de projetar uma diplomacia para lidar com as limitações e os desafios do cenário internacional a médio e longo prazo. 0 novo mapa geopolítico de curto prazo apresenta tanto um eixo do Pacífico liderado pela recente iniciativa da Aliança do Pacífico e do outro eixo Atlântico com o MERCOSUL liderado pelo Brasil.

Neste contexto, aos países do eixo Atlântico se unem por princípios ideológicos e políticos em termos de estratégias econômicas e uma forte defesa da produção interna. De acordo com Muñoz (2012:715-716), este eixo é caracterizado por dois modelos de liderança para a integração regional: o primeiro chamado núcleo duro liderado pela Venezuela é caracterizado para os seus fins geoestratégicos e militares com elementos

integração de facto com os Estados Unidos e a Canadá por meio do TLCAN. O Chile, por outro, com uma estratégia de liberalização unilateral adotada pelo governo militar. 
ideológicos e, o segundo impulsionado pelo Brasil, é caracterizado pela diplomacia cautelosa e se baseia no desenvolvimento econômico e comercial. O Brasil almeja consolidar sua liderança no continente e ser um líder global na região, pode-se citar a União das Nações Sul-Americanas - UNASUL ${ }^{9}$ como a sua proposta mais ambiciosa.

A Aliança Bolivariana para as Américas - ALBA ${ }^{10}$ considera que a Aliança do Pacífico representa o retorno do protagonismo das corporações econômicas sob a premissa de livre mercado e é apresentada como a edição limitada do projeto fracassado proposto pelos Estados Unidos, chamado Área de Livre Comércio das Américas - ALCA.

\begin{abstract}
La Alianza del Pacífico se presenta como un nuevo proyecto recolonizador y neoliberal en contraposición a la propuesta nuestroamericana de integración, representada -por ejemplo- en la Comunidad de Estados Latinoamericanos y Caribeños (CELAC).

El carácter imperialista se esconde detrás de la expresada intención de Estados Unidos de fortalecer relaciones comerciales con el bloque económico y avanzar en la creación del Tratado Trans-Pacífico (TTP), un acuerdo comercial que alienta el acceso de las transnacionales a los recursos naturales estratégicos tales como petróleo, gas, minerales, agua y biodiversidad (ALBA,2014).
\end{abstract}

O informe do Conselho Latino-americano do SELA11 "La Alianza del pacífico en la integración Latinoamericana y Caribeña" indica que as exportações combinadas dos membros da Aliança são maiores do que os dos países sul-americanos do bloco do Mercado Comum do Sul - MERCOSUL ${ }^{12}$, liderados pelo Brasil e pela Argentina (SELA, 2013: 24). O MERCOSUL pode ser o bloco que reflete uma maior concorrência pela Aliança do Pacífico na medida em que promove um regionalismo profundo, a fim de consolidar um mercado comum, além do desenvolvimento de uma agenda política e social com seus Estados membros (SERRANO; GALARRETA, 2013: 24).

\footnotetext{
9 UNASUL é uma organização intergovernamental composta pelos doze Estados da América do Sul, foi criada em 2008 como um impulso para a integração regional em energia, educação, saúde, meio ambiente, infra-estrutura, segurança e democracia. Seus esforços são destinados a aprofundar a ligação entre as nações sul-americanas, com o reconhecimento dos seus objetivos regionais, ativos sociais e recursos energéticos. Disponível em: < http://www.unasursg.org/inicio/organizacion/historia>.

10 Atualmente é chamada Aliança Bolivariana para os Povos de Nossa América / Tratado de Comércio dos Povos (ALBA-TCP).

11 Sistema Econômico Latino-Americano e do Caribe (SELA)

12 Bloco sub-regional integrado pela Argentina, o Brasil, o Paraguai, o Uruguai, a Venezuela e em processo de adesão a Bolívia. Ver: <http://www.mercosur.int/show?contentid=5908\&channel=secretaria>.
} 
Outro aspecto que torna a Aliança do Pacífico como um contra ponto para o MERCOSUL, a UNASUL e a ALBA é sua proximidade com os EUA, especialmente na relação de seus países membros, como no caso da Colômbia para o qual o país do norte é seu maior aliado na luta contra o conflito interno e o narcotráfico. No lado do México, historicamente orientou-se à América do Norte com o Tratado Norte-Americano de Livre Comércio - NAFTA ${ }^{13}$ e com uma dependência econômica dos EUA forte. Os três blocos promovem a autonomia, um modelo de desenvolvimento um pouco protecionista e uma relação mais distante com os EUA (SERRANO; GALARRETA, 2013: 25).

\section{Considerações Finais}

$\mathrm{Na}$ atualidade o processo de integração latino-americano esta dividido em diferentes blocos econômicos que coordenam atividades multilaterais com outras economias em desenvolvimento. Dependendo de seus objetivos, campos de ação, competências e acordos podem ser complementares entre si ou, pelo contrário, rivais para se sobrepõem em suas funções ou enfrentar suas ideologias.

A Aliança do Pacífico surgiu em resposta a fatores externos do sistema internacional, entre os quais pode-se citar a menor influência dos EUA na região, a crise na Europa e o aumento da participação no comércio internacional dos países da Ásia Pacífico, especialmente da China, aumentando a sua influência no mercado mundial.

Neste sentido, a Aliança do Pacífico foi formada pela proposta compartilhada por os seus membros a adotar um modelo de desenvolvimento caracterizado pela liberalização do comércio, a implementação de um regionalismo aberto, com a assinatura de vários Tratados de Livre Comércio (TLC) e a integração econômica como prioridade.

Os países membros da Aliança do Pacífico têm acordos de livre comércio entre eles, o que é visto como uma vantagem comparativa, que pretende explorar as oportunidades de negócios na região da Ásia-Pacífico. No entanto, não é possível identificar qual destes países pode se apropriar do papel de paymaster o líder capaz de

\footnotetext{
${ }^{13}$ Envolve a Canadá, o México e os Estados Unidos e tendo o Chile como associado, numa atmosfera de livre comércio, com custo reduzido para troca de mercadorias entre os três países.
}

Conjuntura Global, Vol.3, n.2, abr.jun., 2014, p. 89-98 
suportar os custos de conduzir o projeto. Neste contexto, o aprofundamento do regionalismo para a integração e o sucesso desta iniciativa deve implicar que os Estados membros possam repensar os conceitos clássicos de soberania (mencionado na primeira parte deste trabalho) e permitir em certa medida sua cessão, o que tradicionalmente tem dificultado os processos existentes.

A consolidação da Aliança é um contrapeso à crescente influência e liderança cada vez mais consolidada do Brasil, que em termos de sua política externa tem sido caracterizado por sua autonomia em relação aos Estados Unidos (que se estende aos países do Eixo Atlântico), enquanto para a Aliança do Pacífico é considerado como um aliado estratégico.

\section{Referências Bibliográficas}

ALIANZA DEL PACÍFICO. ¿Qué es la alianza? La Alianza del Pacífico y sus objetivos. Disponível em: <http://alianzapacifico.net/que_es_la_alianza/la-alianza-delpacifico-y-sus-objetivos/>. Acesso em: 18 Jan. 2014.

ALIANZA Bolivariana Para los Pueblos de Nuestra América - ALBA. Comienza en Colombia la VIII Cumbre de la Alianza del Pacífico. Noticias Portal ALBA. Fev. 2014. Disponível em: http://www.alianzabolivariana.org/ver noticia.php?id=1023. Acceso em: Feb. 2014.

COLOMBIA. Ministerio de Relaciones Exteriores. Comunicaciones Internas. Abecé Alianza del Pacífico. VII Cumbre Alianza del Pacífico. Cali. 23 de mayo de 2013. Disponível em: <http://alianzapacifico.net/documents/ABC_esp.pdf> Acesso em: 15 Jan. 2014.

HEINE, Jorge. Between a rock and a hard place: Latin America and multilateralism after 9/11, In: Newman, Edward; Ramesh Thakur and John Tirman (eds.) Multilateralism under challenge? Power, international order, and structural change, Tokio, Nueva York, París, The United Nations University Press, p. 481-503, 2006. ISBN 13:9788171886722. 
INSTITUTO para la Integración de América Latina y el Caribe - INTAL. Alianza del Pacífico: una nueva iniciativa que una a Chile, Colombia, México y Perú. Carta Mensual INTAL. $\quad \mathrm{N}^{\circ}$ 177, may. 2011. Disponível em: <http://idbdocs.iadb.org/wsdocs/getdocument.aspx?docnum=36385851>. Acesso em: Jan. 2014.

MALAMUD, Carlos. La Alianza del Pacífico: un revulsivo para la integración regional en América Latina. Real Instituto Elcano ARI, 46, 2012. Disponível em: <http://www.realinstitutoelcano.org/wps/portal/rielcano/contenido?WCM GLOB AL CONTEXT=/elcano/elcano es/zonas es/america+latina/ari46-2012>.

MERCADO Integrado Latinoamericano - MILA. MILA suscribió un acuerdo de intención con la Bolsa Mexicana de Valores. Sala de prensa. Noticias 2011 Diciembre/N2. Disponível em: <http://www.mercadomila.com/newsletter>. Acesso em: Dez. 2013.

MENEZES, Roberto Goulart. A Aliança para o Pacífico e a estratégica da integração Sul Americana do Brasil. Anais Eletrônicos do 4ํㅡ Encontro Nacional da Associação Brasileira de Relações Internacionais, Belo Horizonte, 14 p. 2013.

MUÑOZ, Alfredo S. El nuevo mapa político y económico de América Latina: Alianza Pacífico versus UNASUR. Estudios Geográficos, vol. 73, no 273, p. 703-719, 2012. Disponível em: <http://estudiosgeograficos.revistas.csic.es/index.php/estudiosgeograficos/article /viewFile/388/388>. Acesso em: Jan. 2014.

PADULA, Raphael. A Aliança do Pacífico, o Brasil e o poder global na integração regional da América do Sul. Anais Eletrônicos do 4ํㅡ Encontro Nacional da Associação Brasileira de Relações Internacionais, Belo Horizonte, 18 p. 2013.

POSADA, Edgar Vieira. Evolución de las teorías sobre integración en el contexto de las teorías de relaciones internacionales. Papel político. Universidad Javeriana. Bogotá D.C., N. 18, p. 235-290. $2005 . \quad$ Disponível em: <http://revistas.javeriana.edu.co/sitio/papelpolitico/admin/upload/uploads/9.Evo lucion9..pdf>. Acesso em: 20 Nov. 2013.

PROGRAMA de las Naciones Unidas para El Desarrollo - PNUD. Nuestra Democracia. Secretaría General de la Organización de los Estados Americanos. Col. Obras de 
Sociología. México: FCE, PNUD, OEA. 2010. 260 p. ISBN 978-607-16-0448-4. Disponível em: <http://www.oas.org/es/sap/docs/Nuestra_Dem_s.pdf>. Acesso em: Dez. 2014.

SANAHUJA, José Antonio. Del 'regionalismo abierto' al 'regionalismo post-liberal'. Crisis y cambio en la integración regional en América Latina. Anuario de la integración regional de América Latina y el Gran Caribe. Coordinadora Regional de Investigaciones Económicas y Sociales-CRIES. Buenos Aires, v. 7, p. 11-54, 2009. Disponível em: <http://www.iadb.org/intal/intalcdi/PE/2009/02450.pdf>. Acesso em: 20 Jan. 2014.

SERRANO, Lorena Oyarzún; GALARRETA, Federico Rojas De. La alianza del pacífico en América Latina ¿Contrapeso regional?. Cuadernos sobre Relaciones Internacionales, Regionalismo y Desarrollo. Mérida Vol. 8. No. 16, p. 9-30. Jul-Dic. 2013. ISSN 1856349X. Disponível em:

http://www.saber.ula.ve/bitstream/123456789/38538/3/articulo 1.pdf $>$. 